\title{
Risk of COVID-19 Infection and Associated Factors Among Healthcare Workers: A Cross-Sectional Study at Eka Kotebe Treatment Center in Ethiopia
}

\author{
Hawi Hussen ' \\ Zewdie Aderaw Alemu ${ }^{2}$ \\ 'Yekatit 12 Hospital, Addis Ababa Health \\ Bureau, Ministry of Health, Addis Ababa, \\ Ethiopia; ${ }^{2}$ Public Health Department, \\ Debre Markos University, Debre \\ Mark'os, Ethiopia
}

Background: Healthcare worker-associated COVID-19 infection is a worldwide problem. The magnitude of exposure risk to COVID-19 infections in Ethiopia is rapidly increasing following its spread in the country. However, studies about the risk of COVID-19 infection among healthcare workers and factors associated with risk of COVID-19 infection are lacking in Ethiopia.

Objective: The study investigated level of risk of COVID-19 infection and associated factors among healthcare workers at Eka Kotebe COVID-19 treatment center.

Methods: A facility-based cross-sectional study was conducted from September to October 2020 to determine risk of COVID-19 infection and associated factors at Eka Kotebe COVID-19 treatment center. In total, 318 healthcare workers participated in the study. Data was analyzed using SPSS version 25. A binary logistic regression model was used to evaluate the risk of COVID-19 infection among healthcare workers.

Results: A total of 243 (76\%) healthcare workers had a high exposure risk of COVID-19 infection. Department of healthcare workers, ICU department workers [AOR: 6.545, 95\% CI; (1.79-23.97)], long working hours [AOR: 9.224, 95\% CI; (2.00-42.61)], inadequate supply of PPE [AOR: $0.318,95 \%$ CI; (0.14-0.75)], lack of access to alcohol-based hand rub [AOR: 0.093 , 95\% CI; (0.01-0.98)], providing care within one meter of COVID-19 patients [AOR: 20.633, 95\% CI; (3.88-109.76)], and direct contact with an environment in which a COVID-19 patient received care [AOR: 9.600, 95\% CI; (1.05-84.50)] were found to be risk factors for COVID-19 infection.

Conclusion: Healthcare workers face a high risk of COVID-19 infection while providing care for COVID-19 patients. Proper use and adequate supply of PPE and the implementation of basic infection prevention and control with frequent protocol revision and strict supervision are crucial to limit exposure risk to COVID-19 among healthcare workers.

Keywords: coronavirus, SARS-COV-2, COVID-19, healthcare workers, exposure risk factors, Addis Ababa, Ethiopia, Africa

\section{Background}

A new coronavirus that previously has not been identified in humans emerged in Wuhan city, China, on 31 December 2019. The World Health Organization (WHO) named the disease caused by this virus COVID-19 (for coronavirus disease identified in 2019). ${ }^{1,2}$ The virus has spread to almost every country, resulting in more than 117 million COVID-19 cases worldwide, causing more than 2.61 million deaths as of March 2021. The first case of COVID-19 on the continent of Africa was reported on 14 February 2020, and by 13 May cases had been reported in all 54 countries. On
Correspondence: Hawi Hussen Department of Internal Medicine, Yekatit 12 Hospital, Addis Ababa, Ethiopia Tel +251 91 141 7622

Email hawihussen7@gmail.com 
13 March 2020, the epidemic reached Ethiopia and it had already infected more than 168,335 people and caused 2451 deaths as of March 2021. ${ }^{3-6}$ The pandemic has broken the healthcare system and filled hospitals and emptied public spaces in areas with sustained transmission of COVID-19. The damage to health, wealth and wellbeing has already been enormous. ${ }^{7,8}$

COVID-19 is a serious global health problem costing the lives of many people, including healthcare workers (HCWs). HCWs accounted for a large proportion of COVID-19 infections during the pandemic of early 2020. COVID-19 cases in HCWs have been reported since early in the outbreak. At the beginning of the outbreak in Wuhan region, China, 1716 HCWs were infected by COVID-19. ${ }^{9}$ Reports indicate that at least $1311 \mathrm{HCWs}$ tested positive for COVID-19 infection in Ethiopia as of 17 September $2020 .{ }^{10}$ A crucial challenge for the country is the very low ratio of HCWs per 10,000 patients, as well as a weak healthcare system. Nowadays, COVID-19 is the most serious threat to HCWs and causes the highest level of anxiety among them in many countries, including Ethiopia. Contact, potential droplets and numerous high risk unprotected exposures are factors that may place HCWs at higher risk of infection. ${ }^{11}$ Factors fueling the exposure risk among HCWs are high work load, lack of PPE supplies and the work environment. ${ }^{12} \mathrm{HCW}$ s are vital resources; their health and safety are crucial. Measures to mitigate HCWs' exposure risk to COVID-19 infection support the effort to combat the pandemic and protect the health system.

HCWs' exposure risk to COVID-19 is a current problem. Comprehensive analysis of risk of COVID-19 infection among HCWs and its risk factors are lacking in Ethiopia. The study, therefore, investigated exposure risk of COVID-19 infection among HCWs and factors associated with risks of COVID-19 infection.

\section{Methods and Materials}

\section{Study Area and Period}

The research was conducted in Eka Kotebe COVID-19 treatment center, the first COVID-19 treatment center in Ethiopia. It is located in Yeka sub-city, in Addis Ababa city administration. It is a large medical facility, with a 600-bed capacity. It was inaugurated in September 2019. With the outbreak of COVID-19 the hospital underwent thorough reconstruction and was transformed into a COVID-19 treatment center where COVID-
19 patients are quarantined and treated. The study was carried out in the center from September to October 2020.

\section{Study Design}

A facility-based cross-sectional study design was conducted among 318 HCWs working in the treatment center.

\section{Participants}

The study population includes physicians, nurses, pharmacists, laboratory personnel, health officers, psychiatrists, environmental health officers, anesthesiologists and support staff (cleaners, spray man, porters) working at Eka Kotebe COVID-19 treatment center. The participants were selected from each department of the treatment center using a proportionate stratified random sampling technique.

\section{Measurements}

The dependent variable was level of exposure risk of HCWs. The independent variables include demographic factors (age, sex, work experience, department, work hours, pre-existing health condition, HCW role and education level), exposure type factors (providing care within one meter, performing or assisting AGPs, direct contact with an environment in which a COVID-19 patient received care and prolonged face-to-face exposure) and IPC measure factors (PPE availability and use, training, availability of alcohol-based hand rub and following the recommended IPC measures.

\section{Data Collection Procedures and}

\section{Instruments}

A structured questionnaire was administered by an interviewer. COVID-19 infection exposure risk level was assessed based on WHO and CDC risk assessment tools. According to the criteria, a "high exposure risk to COVID19" was defined as HCWs performing at least one of the following activities: (1) provide direct care to a confirmed COVID-19 patient; (2) had face-to-face contact (within 1 meter) with a confirmed COVID-19 patient in a healthcare facility; (3) were present when any AGP was performed on the patient; and (4) had direct contact with the environment in which a confirmed COVID-19 patient was cared for without appropriate PPE. "Low exposure risk to COVID-19" was defined as HCWs who do not fulfill the above criteria. $^{13,14}$ 


\section{Data Collectors' Selection and Training}

Data was collected by three BSc nurses and supervision was conducted by the principal investigator. Data collectors were trained by the principal investigator on the study instrument, consent form and data collection procedure.

\section{Data Quality Management}

Data collection tools pre-tested whether the acceptable level of internal reliability exists, to assure validity. The questionnaire was designed based on $\mathrm{WHO}$ and CDC HCWs' COVID-19 exposure risk assessment tool. Data collectors were trained and regularly supervised and the principal investigator made sure all the necessary data was properly collected and checked for completeness and consistency of filled questionnaire.

\section{Data Processing and Analysis}

Data were cleaned, coded and entered, and all statistical analyses were performed using SPSS version 25.0. Tables were used to summarize the frequencies and proportions of the variables. A binary logistic regression model was used to evaluate risk of COVID-19 infection. A bivariate followed by a multivariate regression model was employed to evaluate the association between risk factors and risk of COVID-19 infection. Variables significant at a p-value of 0.05 in the bivariate analysis were selected for the multivariate regression analysis. An odds ratio (OR) with a $95 \%$ confidence interval (CI) was used to report the association between exposure risk and risk factors.

A p-value of 0.05 for the models fitted separately was considered statistically significant. After the logistic regression model was fitted, the overall goodness of fit of the model tested the adequacy of the model.

\section{Ethical Considerations}

The study was conducted in compliance with the Declaration of Helsinki. The study received ethical approval from the Eka Kotebe COVID-19 treatment center review board (Reference number: Eka/150-5-31). Written informed consent was obtained from study participants. Participants were also assured that, if they agreed to participate, they would have the right to withdraw from the study at any time. Only those individuals who volunteered to participate in the research were approached to complete the questionnaires. Confidentiality and anonymity were maintained.

\section{Results}

\section{Demographic Characteristics of the Respondents}

Overall, the mean (SD) age was 28.1 (5.1) years. Among the 318 HCWs, $243(76.4 \%)$ were between the age of 25-34 years, $176(55 \%)$ were male and $142(45 \%)$ were female. Fifty-one (16\%) were medical doctors, 157 (49.4\%) were nurses, 13 (4.1\%) were health officers, $11(3.5 \%)$ were pharmacists and the remaining $86(27.0 \%)$ were laboratory personnel, anesthetists, X-ray technicians, biomedical engineers, environmental health officers, psychiatrists, psychologists, porters, the spray man and cleaners (Table 1).

\section{Risk of COVID-19 Infection Characteristics}

Findings demonstrated that HCWs have a high exposure risk of COVID-19 infection. Over three-quarters (76\%) of HCWs had a high risk of exposure to COVID-19 infection.

\section{Demographic Factors}

Table 2 shows crude statistics relating to the demographic risk factors for COVID-19 infection among HCWs.

The role, department and working hours of HCWs were identified as the major demographic risk factors for COVID-19 infection. Medical doctors were 5 times more exposed to COVID-19 infection than other HCWs [OR: 4.746, 95\% CI; (1.92-11.73)] and nurses were 4 times more exposed to COVID-19 infection than other HCWs [OR: 3.987, 95\% CI; (2.18-7.30)].

Healthcare workers working in inpatient and intensive care units were 3 times [OR: $3.044,95 \%$ CI; (1.58-5.85)] and 4 times [OR: 3.908, 95\% CI; (1.62-9.46)] more exposed to COVID-19 infection than other HCWs. Working hours was another variable that showed an association with risk of COVID-19 infection. HCWs who worked more than eight hours per day were 3 times more exposed to COVID-19 infection than those who worked for eight hours or fewer [OR: $3.309,95 \% \mathrm{CI}$; (1.40-7.88)] (Table 2).

\section{IPC Factors}

Table 3 shows crude statistics relating to IPC factors as COVID-19 infection risks among HCWs. IPC factor variables include availability of PPE, availability of alcohol-based hand rub at the point of care and following the recommended hand hygiene procedure showed significant associations with risk of COVID-19 infection in the analysis. Those HCWs who did not 
Table I Demographic Characteristics of Healthcare Workers at Eka Kotebe COVID-19 Treatment Center in Ethiopia, October, $2020(\mathrm{~N}=318)$

\begin{tabular}{|c|c|c|}
\hline Characteristics & Frequency $(n)$ & Percent (\%) \\
\hline Mean age (SD) & $28.1(5.1)$ & \\
\hline \multicolumn{3}{|l|}{ Age } \\
\hline$<25$ Years & 44 & 13.8 \\
\hline 25-34 Years & 243 & 76.4 \\
\hline $35-44$ Years & 25 & 7.9 \\
\hline$>45$ Years & 6 & 1.9 \\
\hline \multicolumn{3}{|l|}{ Sex } \\
\hline Male & 176 & 55.3 \\
\hline Female & 142 & 44.7 \\
\hline \multicolumn{3}{|l|}{ Years of experience } \\
\hline Less than 2 years & 96 & 30.2 \\
\hline $2-5$ years & 184 & 57.8 \\
\hline$>5$ years & 38 & 12 \\
\hline \multicolumn{3}{|l|}{ Role of healthcare personnel } \\
\hline Medical doctor & 51 & 16.0 \\
\hline Nurse & 157 & 49.4 \\
\hline Health officer & 13 & 4.1 \\
\hline Pharmacist & 11 & 3.5 \\
\hline Other $^{\ddagger}$ & 86 & 27.0 \\
\hline \multicolumn{3}{|l|}{ Working department } \\
\hline Inpatient & 176 & 55.3 \\
\hline Intensive care unit & 61 & 19.2 \\
\hline Laboratory & 6 & 1.9 \\
\hline Pharmacy & 17 & 5.3 \\
\hline Other $^{\dagger}$ & 57 & 17.9 \\
\hline \multicolumn{3}{|l|}{ Work hours per day } \\
\hline$\leq 8$ hours & 295 & 92.8 \\
\hline$>8$ hours & 23 & 7.2 \\
\hline \multicolumn{3}{|l|}{ Educational level } \\
\hline Primary/ Secondary & 41 & 12.9 \\
\hline Diploma & 22 & 6.9 \\
\hline MD/BSC & 238 & 74.8 \\
\hline Specialty/ MSC/MPH & 17 & 5.3 \\
\hline \multicolumn{3}{|l|}{$\begin{array}{l}\text { Underlying disease or pre- } \\
\text { existing condition(s) }\end{array}$} \\
\hline Yes & 16 & 5.0 \\
\hline No & 302 & 95 \\
\hline
\end{tabular}

Notes: ${ }^{\ddagger}$ Psychiatrist, nutritionist, midwife, laboratory personnel, x-technician, biomedical engineer, environmental health officer, anesthetist, social worker, clinical psychologist, porter, data manager, cleaner and spray man. ${ }^{\dagger}$ Psychiatric department, operation room, radiology, management team and IPC department.

have an adequate supply of PPE were 70\% [OR: 0.295, 95\% CI; (0.16-0.54)] more likely to be exposed to COVID-19 infection than those who had an adequate supply of PPE. HCWs who did not have access to alcohol-based hand rub at the point of care were $80 \%$ [OR: $0.199,95 \% \mathrm{CI}$; $(0.05-0.86)$ ] more likely to be exposed to COVID-19 infection than those who had access to alcohol-based hand rub (Table 3).

\section{Exposure Type Factors}

Table 4 presents crude statistics relating to exposure type risk factors for COVID-19 infection among HCWs.

Healthcare workers who were within one meter of a COVID-19 patient were 26 times [OR: 26.158, 95\% CI; (6.27-109.11)] more likely to be exposed to COVID-19 infection than those $\mathrm{HCW}$ who were not within one-meter distance of a COVID-19 patient. HCWs who performed or assisted with any aerosol generating procedure (AGP) or were present in the room when one was performed were 23 times [OR: 23.264, 95\% CI; (3.16-171.10)] more likely to be exposed to COVID-19 infection than those who did not perform or assist AGPs or were present in the room when one was performed. HCWs who had direct contact with an environment in which a COVID-19 patient received care (eg, bed, linen, medical equipment, frequently touched surfaces and bathroom) were 36 times [OR: 35.865, 95\% CI; (4.90-262.73)] more likely to be exposed to COVID-19 infection than those who did not have such direct contact. HCWs who had prolonged face-to-face exposure ( $>15$ minute) were 4 times [OR: 3.589, 95\% CI; (2.07-6.23)] more likely to be exposed to COVID-19 infection than those who did not have prolonged face-to-face exposure ( $>15$ minute) (Table 4$)$.

\section{Multivariate Logistic Regression Analysis}

Multivariate binary logistic regression analysis showed that HCWs' department, working hours, availability of PPE, availability of alcohol-based hand rub, providing care within one meter distance and direct contact with an environment in which a COVID-19 patient received care were significantly associated with the risk of COVID-19 infection.

Regarding HCWs' department, those working in the ICU were 7 times [AOR: 6.545, 95\% CI; (1.79-23.97)] more likely to be exposed to COVID-19 infection than those working in other departments. HCWs working for more than 8 hours per day were 9 times [AOR: 9.224, 95\% CI; (2.00-42.61)] more likely to be exposed to COVID-19 infection than those who work for 8 hours or fewer. HCWs with an inadequate supply of PPE were 68.2\% [AOR: 0.318, 95\% CI; (0.14-0.75)] more likely to be exposed to COVID-19 infection than those who had an adequate supply of PPE. HCWs without access to alcohol-based hand rub at the point of care were 90.7\% [AOR: 0.093, 95\% CI; (0.01-0.98)] more likely 
Table 2 Crude Statistics Relating to Demographic Risk Factors for COVID-19 Infection at Eka Kotebe COVID-19 Treatment Center in Ethiopia, October, 2020

\begin{tabular}{|c|c|c|c|c|}
\hline \multirow{2}{*}{ Factors } & \multicolumn{2}{|c|}{ Risk } & \multirow[t]{2}{*}{ COR $(95 \% \mathrm{Cl})$} & \multirow{2}{*}{ p value } \\
\hline & High (\%) & Low (\%) & & \\
\hline \multicolumn{5}{|l|}{ Age } \\
\hline$<25$ & $34(77.3)$ & $10(22.7)$ & $3.40(0.592-19.541)$ & 0.170 \\
\hline $25-34$ & 192(79) & $5 I(2 I)$ & $3.63(0.7|I-| 8.5 \mid 5)$ & 0.121 \\
\hline $35-44$ & $14(56)$ & II (44) & $\mathrm{I} .27(0.2 \mid 4-7.58 \mathrm{I})$ & 0.791 \\
\hline$>45$ & $3(50)$ & $3(50)$ & 1.00 & \\
\hline \multicolumn{5}{|l|}{ Sex } \\
\hline Male & $134(76.1)$ & $42(23.9)$ & $1.035(0.615-1.744)$ & 0.896 \\
\hline Female & $109(76.8)$ & $33(23.2)$ & 1.00 & \\
\hline \multicolumn{5}{|l|}{ Years of experience } \\
\hline$<2$ years & $67(74.4)$ & $23(25.6)$ & $1.515(0.667-3.442)$ & 0.321 \\
\hline $2-5$ years & 133(78.7) & $36(21.3)$ & $1.933(0.906-4.125)$ & 0.088 \\
\hline$>5$ years & $25(65.8)$ & $13(34.2)$ & 1.00 & \\
\hline \multicolumn{5}{|c|}{ Role of healthcare workers } \\
\hline Medical doctor & $44(86.3)$ & $7(13.7)$ & $4.746(1.921-11.728)$ & $0.001 * * *$ \\
\hline Nurse & I $32(84.1)$ & $25(15.9)$ & $3.987(2.179-7.295)$ & $0.000 * * *$ \\
\hline Health officer & II (84.6) & $2(15.4)$ & $4.153(0.868-19.881)$ & 0.075 \\
\hline Pharmacist & $7(63.6)$ & $4(36.4)$ & $\mathrm{I} .32 \mathrm{I}(0.360-4.85 \mathrm{I})$ & 0.674 \\
\hline Other $^{\ddagger}$ & $49(57.0)$ & $37(43.0)$ & 1.00 & \\
\hline \multicolumn{5}{|l|}{ Working department } \\
\hline Inpatient & |44(81.8) & $32(18.2)$ & $3.044(1.584-5.850)$ & $0.00 I^{* * *}$ \\
\hline Intensive care unit & $52(85.2)$ & $9(14.8)$ & $3.908(1.615-9.457)$ & $0.002^{* * *}$ \\
\hline Laboratory & $5(83.3)$ & I (16.7) & $3.382(0.37 I-30.872)$ & 0.280 \\
\hline Pharmacy & $7(4 \mid .2)$ & $10(58.8)$ & $0.474(0.157-1.424)$ & 0.183 \\
\hline Other $^{\dagger}$ & $34(59.6)$ & $23(40.4)$ & 1.00 & \\
\hline \multicolumn{5}{|l|}{ Work hours per day } \\
\hline$\leq 8$ hours & $220(94.8)$ & $12(5.2)$ & 1.00 & $0.007^{* * *}$ \\
\hline$>8$ hours & $58(84.1)$ & II(I5.9) & $3.309(1.395-7.884)$ & \\
\hline \multicolumn{5}{|l|}{ Educational level } \\
\hline Primary/Secondary & $18(43.9)$ & $23(56.1)$ & $0.326(0.097-1.096)$ & 0.070 \\
\hline Certificate/Diploma & $14(63.6)$ & $8(36.4)$ & $0.729(0.188-2.834)$ & 0.648 \\
\hline MD/BSC & $199(83.6)$ & $39(16.4)$ & $2.126(0.709-6.376)$ & 0.178 \\
\hline Specialty/ MSC/MPH & $12(70.6)$ & $5(29.4)$ & 1.00 & \\
\hline \multicolumn{5}{|l|}{$\begin{array}{l}\text { Underlying disease or pre- } \\
\text { existing condition(s) }\end{array}$} \\
\hline Yes & $10(62.5)$ & $6(37.5)$ & $0.494(0.173-1.406)$ & 0.186 \\
\hline No & $233(77.2)$ & $69(22.8)$ & 1.00 & \\
\hline
\end{tabular}

Notes: Significant at: ${ }^{* * *} p \leq 0.0 \mathrm{I}, \mathrm{I}=$ Reference category. ${ }^{\dagger}$ Psychiatrist, nutritionist, midwife, laboratory personnel, $\mathrm{x}$-technician, biomedical engineer, environmental health officer, anesthetist, social worker, clinical psychologist, porter, data manager, cleaner and spray man. 'Psychiatric department, operation room, radiology, management team and IPC department.

to be exposed to COVID-19 infection than those who had access to alcohol-based hand rub. HCWs who provided care within one meter of a COVID-19 patient were 21 times [AOR: 20.633, 95\% CI; (3.88-109.76)] more likely to be exposed to COVID-19 infection than those not working within one meter of a COVID-19 patient. HCWs who had direct contact with an environment in which a COVID-19 patient received care (eg, bed, linen, medical equipment, frequently-touched surfaces, bathroom) were 10 times [AOR: 9.600, 95\% CI; 
Table 3 Crude Statistics Relating to IPC Risk Factors for COVID-I 9 Infection at Eka Kotebe COVID-I9 Treatment Center in Ethiopia, October, 2020

\begin{tabular}{|c|c|c|c|c|}
\hline \multirow[t]{2}{*}{ Factors } & \multicolumn{2}{|c|}{ Risk } & \multirow[t]{2}{*}{ COR $(95 \% \mathrm{Cl})$} & \multirow[t]{2}{*}{ p value } \\
\hline & High (\%) & Low (\%) & & \\
\hline \multicolumn{5}{|l|}{ Training } \\
\hline Yes & $216(77.7)$ & $62(22.3)$ & $1.887(0.908-3.922)$ & 0.089 \\
\hline No & $24(64.9)$ & 13(35.1) & 1.00 & \\
\hline \multicolumn{5}{|l|}{ Availability of PPE } \\
\hline Yes & $31(55.4)$ & $25(44.6)$ & $0.295(0.160-0.544)$ & $0.000 * * *$ \\
\hline No & $210(80.8)$ & $50(19.2)$ & 1.00 & \\
\hline \multicolumn{5}{|l|}{ PPE use } \\
\hline Never & $7(87.5)$ & $\mathrm{I}(12.5)$ & $2.500(0.298-20.957)$ & 0.398 \\
\hline Rarely & $7(100)$ & $0(0)$ & $5769(0.000-0.000)$ & 0.999 \\
\hline Occasionally & $14(73.7)$ & $5(26.3)$ & $1.000(0.339-2.954)$ & 1.000 \\
\hline Most of the time & $101(77.7)$ & $29(22.3)$ & $1.244(0.719-2.153)$ & 0.436 \\
\hline Always & $112(73.7)$ & $40(26.3)$ & 1.00 & \\
\hline \multicolumn{5}{|c|}{ Availability of alcohol-based hand rub } \\
\hline Yes & $208(74.3)$ & $72(25.7)$ & $0.199(0.046-0.856)$ & $0.030 * *$ \\
\hline No & $29(93.5)$ & $2(6.5)$ & 1.00 & \\
\hline \multicolumn{5}{|l|}{ Hand hygiene } \\
\hline Never & $27(77.1)$ & $8(22.9)$ & I.572(0.658-3.760) & 0.309 \\
\hline Rarely & $32(94.4)$ & $3(8.6)$ & $4.970(1.438-17.175)$ & $0.011 * *$ \\
\hline Occasionally & $20(80.0)$ & $5(20.0)$ & $1.864(0.654-5.313)$ & 0.244 \\
\hline Most of the time & $76(80.8)$ & $18(19.2)$ & $1.967(1.044-3.706)$ & $0.036 * *$ \\
\hline Always & $88(68.2)$ & $4 I(3 I .8)$ & 1.00 & \\
\hline
\end{tabular}

Note: Significant at: $* * p \leq 0.05, * * * p \leq 0.0$ I, I =Reference category.

Table 4 Crude Statistics Relating tf Exposure Type Risk Factors for COVID-I 9 Infection at Eka Kotebe COVID-19 Treatment Center in Ethiopia, October, 2020

\begin{tabular}{|c|c|c|c|c|}
\hline \multirow[t]{2}{*}{ Factors } & \multicolumn{2}{|c|}{ Risk } & \multirow[t]{2}{*}{ OR $(95 \% \mathrm{Cl})$} & \multirow[t]{2}{*}{ p value } \\
\hline & High (\%) & Low (\%) & & \\
\hline \multicolumn{5}{|l|}{ Within one meter } \\
\hline Yes & $101(98.1)$ & $2(1.9)$ & $26.158(6.27-109.111)$ & $0.000 * * *$ \\
\hline No & $139(65.9)$ & $72(34.1)$ & 1.00 & \\
\hline \multicolumn{5}{|l|}{ Perform AGPs } \\
\hline Yes & $58(98.3)$ & $\mathrm{I}(\mathrm{I} .7)$ & $23.264(3.163-|7| .100)$ & $0.002^{* * *}$ \\
\hline No & I82(7I.4) & $73(28.6)$ & 1.00 & \\
\hline \multicolumn{5}{|l|}{ Direct contact-environment } \\
\hline Yes & $79(98.8)$ & $\mathrm{I}(\mathrm{I} .2)$ & $35.865(4.896-262.732)$ & $0.000 * * *$ \\
\hline No & $163(67.4)$ & $74(30.6)$ & 1.00 & \\
\hline \multicolumn{5}{|l|}{ Prolonged face-to-face exposure } \\
\hline Yes & $152(86.4)$ & $24(13.6)$ & $3.589(2.069-6.225)$ & $0.000 * * *$ \\
\hline No & $90(63.8)$ & $5 I(36.2)$ & 1.00 & \\
\hline
\end{tabular}

Note: Significant at: $* * * p \leq 0.0$ I, I=Reference category. 
(1.05-84.50)] more likely to be exposed to COVID-19 infection than those who did not have direct contact with such an environment (Table 5).

\section{Discussion}

In this study, the overall level of exposure risk to COVID19 infection among HCWs was $76 \%$. Our findings complement earlier data in America showing that nearly 55\% of HCWs faced exposure risk in the healthcare setting. ${ }^{15}$ Based on 48 publications reviewed, the proportion of HCWs who have tested positive for COVID-19 varies from $0 \%$ to $52 \%{ }^{16}$

HCWs who work in the ICU department were 7 times more likely to be exposed to COVID-19 infection than those in other departments. This result complements previous research indicating that the high

Table 5 Multivariate Logistic Regression Analyses of the Relative Effect of Demographic, IPC and Types of Exposure Factors of COVID-19 Infection at Eka Kotebe COVID-19 Treatment Center in Ethiopia, October, 2020

\begin{tabular}{|c|c|c|c|c|}
\hline \multirow[t]{2}{*}{ Variables } & \multicolumn{2}{|c|}{ Risk } & \multirow[t]{2}{*}{ COR $(95 \% \mathrm{Cl})$} & \multirow[t]{2}{*}{ AOR $(95 \% \mathrm{Cl})$} \\
\hline & High & Low & & \\
\hline \multicolumn{5}{|l|}{ Role of HCWs } \\
\hline Medical doctor & 44 & 7 & $4.746(1.921-11.728)^{* * *}$ & $3.174(0.928-10.856)$ \\
\hline Nurse & 132 & 25 & $3.987(2.179-7.295)^{* * *}$ & $1.233(0.503-3.021)$ \\
\hline Health officer & 11 & 2 & $4.153(0.868-19.881)$ & $1.452(0.212-9.938)$ \\
\hline Pharmacist & 7 & 4 & $|.32|(0.360-4.85 \mathrm{I})$ & $2.139(0.14 \mid-32.38 I)$ \\
\hline Other & 49 & 37 & 1.00 & 1.00 \\
\hline \multicolumn{5}{|l|}{ Working department } \\
\hline Inpatient & 144 & 32 & $3.044(1.584-5.850) * * *$ & $2.772(0.962-7.988)$ \\
\hline Intensive care unit & 52 & 9 & $3.908(1.615-9.457) * * *$ & $6.545(1.787-23.966) * *$ \\
\hline Laboratory & 5 & 1 & $3.382(0.37 I-30.872)$ & $1.069(0.054-21.204)$ \\
\hline Pharmacy & 7 & 10 & $0.474(0.157-1.424)$ & $0.288(0.027-3.032)$ \\
\hline Other & 34 & 23 & 1.00 & \\
\hline \multicolumn{5}{|l|}{ Work hours per day } \\
\hline$\leq 8$ hours & 220 & 12 & 1.00 & 1.00 \\
\hline$>8$ hours & 58 & 11 & $3.309(1.395-7.884) * * *$ & $9.224(1.997-42.613)^{* * * *}$ \\
\hline \multicolumn{5}{|l|}{ Availability of PPE } \\
\hline Yes & 31 & 25 & $0.295(0.160-0.544) * * *$ & $0.318(0.135-0.748) * * *$ \\
\hline No & 210 & 50 & 1.00 & 1.00 \\
\hline \multicolumn{5}{|c|}{ Availability of alcohol-based hand rub } \\
\hline Yes & 208 & 72 & $0.199(0.046-0.856) * *$ & $0.093(0.009-0.979) * *$ \\
\hline No & 29 & 2 & 1.00 & 1.00 \\
\hline \multicolumn{5}{|l|}{ One-meter distance } \\
\hline Yes & 86 & 1 & $26.158(6.27-109.111) * * *$ & $20.633(3.879-109.755) * *$ \\
\hline No & 153 & 74 & 1.00 & 1.00 \\
\hline \multicolumn{5}{|l|}{ Perform AGPs } \\
\hline Yes & 69 & 1 & $23.2640(3.163-171.100) * * *$ & $5.133(0.584-45.125)$ \\
\hline No & $17 \mid$ & 74 & 1.00 & 1.00 \\
\hline \multicolumn{5}{|c|}{ Environment: frequently-touched surfaces } \\
\hline Yes & 152 & 24 & $35.865(4.896-262.732) * * *$ & $9.600(1.053-87.494)^{* *}$ \\
\hline No & 90 & 51 & 1.00 & 1.00 \\
\hline \multicolumn{5}{|c|}{ Prolonged face-to-face exposure } \\
\hline Yes & 152 & 24 & $3.589(2.069-6.225) * * *$ & $1.56 \mid(0.749-3.351)$ \\
\hline No & 90 & 51 & 1.00 & 1.00 \\
\hline
\end{tabular}

Note: Significant at: $* * p \leq 0.01, * * * p \leq 0.001,1=$ Reference category. 
risk group comprises those conducting interventional medical or surgical procedures that generate respiratory aerosols, including those in the respiratory department, infection department, ICU and surgical department, who were 2 times more likely to develop COVID-19 compared with those working in low-risk clinical departments. ${ }^{11}$ This may be due to workload, long work hours and providing direct care to patients.

In this study HCWs who work for more than 8 hours per day were 9 times more likely to be exposed to COVID-19 infection than those who work for 8 hours or fewer per day, which is consistent with a study conducted in China that showed longer hours to be a risk factor for COVID-19 infection. ${ }^{11}$ Other studies ${ }^{17,18}$ also identify work overload, long time exposure to infected patients, working under pressure and longer duty hours to be risk factors for COVID-19 infection.

Those HCWs who did not have an adequate supply of PPE were $68.2 \%$ more likely to be exposed to COVID-19 infection than those who had an adequate supply of PPE. Similar to our finding, previous research has proven that an inadequate supply of PPE increases risk of COVID-19 infection. This result was supported by a prospective cohort study done among HCWs in the UK and America. Inadequate PPE availability was associated with a subsequent $26 \%$ increased risk of COVID-19. ${ }^{15}$ An inadequate supply of PPE was shown to be one of the risk factor for HCWs with a high incidence of COVID-19 infections. ${ }^{19-21}$

HCWs who did not have access to alcohol-based hand rub at the point of care were $90.7 \%$ more likely to be exposed to COVID-19 infection than those who had access to alcohol-based hand rub. This finding is consistent with the results of other research. ${ }^{11,22,23}$

HCWs who were within one meter of a COVID-19 patient were 21 times more likely to be exposed to COVID-19 infection than those who were not within one meter of a COVID-19 patient. Aerosol (droplets from the patient's mouth or nose) spread from an infected patient to the HCW and the distance of the source to the recipient influences the likelihood of infection. ${ }^{24}$

HCWs who have direct contact with an environment in which a COVID-19 patient received care were 10 times more likely to be exposed to COVID-19 infection than those who did not have such direct contact. Similarly, a retrospective analysis ${ }^{18}$ and a rapid review ${ }^{25}$ revealed a lack of established practices of infection prevention and control and direct contact with contaminated surfaces as important risk factors for COVID-19.

\section{Conclusions}

The study pointed out that HCWs are exposed to a high risk of COVID-19 infection at the treatment center. Working in the ICU department, long working hours, inadequate supply of PPE, lack of access to alcoholbased hand rub at the point of care, providing care within one meter of a COVID-19 patient and direct contact with an environment in which a COVID-19 patient received care were risk factors for COVID-19 infection. Proper use and adequate supply of PPE and the implementation of basic infection prevention and control measures with frequent protocol revision and strict supervision are essential to minimize exposure risk of HCWs to COVID-19 infection.

\section{Abbreviations}

AGPs, aerosol-generating procedures; CDC, Centers for Disease Control; COVID-19, coronavirus disease-2019; HCWs, healthcare workers; ICU, intensive care unit; IPC, infection prevention and control; PPE, personal protective equipment; WHO, World Health Organization.

\section{Data Sharing Statement}

The authors approve all data underlying the findings being completely accessible without limitation. https://drive.goo gle.com/file/d/1C8RERhrgMvATTkAoLTcvkCvHf8Nf7fiv/ view? usp=sharing.

\section{Ethics Approval and Consent to Participate}

Participation in this study was voluntary. Participants were assured, in a written informed consent letter, that their responses would remain anonymous. They were asked to respond to the survey if they agreed to the informed consent. The study received ethical approval from the Eka Kotebe COVID-19 treatment center review board (Reference number: Eka/150-5-31). The study was conducted in compliance with the Declaration of Helsinki.

\section{Consent for Publication}

All authors grant the International Journal of General Medicine permission to publish this study.

\section{Acknowledgments}

The authors extend their appreciation to Dr. Yared Agidew (CEO of Eka Kotebe COVID-19 treatment center) and 
staff at Eka Kotebe for providing us with the necessary information.

\section{Author Contributions}

All authors made substantial contribution to conception and design, acquisition of data, or analysis and interpretation of data; took part in drafting the article or revising it critically for important intellectual content; agreed to submit to the current journal; gave final approval of the version to be published; and agree to be accountable for all aspects of the work.

\section{Disclosure}

The authors declare that they have no competing interests in this work.

\section{References}

1. International Pharmaceutical Federation. Corona virus SARS-CoV-2/ COVID-19 pandemic: information and interim guidelines for pharmacists and the pharmacy workforce. International Pharmaceutical Federation; 2020. Available from: http://www.fip.org/coronavirus. Accessed June 20, 2020.

2. WHO. Novel coronavirus (2019-nCov)—Situation Report 222020. Available from: https://apps.who.int/iris/handle/10665/330991. Accessed June 7, 2020.

3. United Nations. Policy Brief: impact of COVID-19 in Africa; 2020. Available from: https://www.uneca.org/archive/publications/policybrief-impact-covid-19-africa. Accessed June 25, 2020.

4. UNECA. COVID-19 in Africa Protecting Lives and Economies; 2020. Available from: https://repository.uneca.org/handle/10855/ 43756. Accessed September 2, 2020.

5. EPHI. The Ethiopian public Health Institute COVID-19 daily update 2020. Available from: www.ephi.gov.et. Accessed October 26, 2020.

6. MOH. Ethiopia Ministry of Health COVID -19 daily updates 2020 Available from: www.moh.gov.et/ejcc/en. Accessed October 26, 2020

7. Bill G. Pandemic I: the First Modern Pandemic. Washington post; 2020. Available from: https://www.gatesnotes.com/Health/PandemicInnovation. Accessed June 2, 2020.

8. Johns Hopkins University. Corona virus database; 2020. Available from: https://coronavirus.jhu.edu/data/new-cases. accessed 6 October 2020

9. News TB. A total of 1716 Chinese HCWs were infected by COVID19 till February 11, 2020; 2020. Available from: https://sciencespeaks blog.org/2020/02/14/china-discloses-1716-healthcare-workers-withcovid-19-feb-14-2020/. Accessed June 1, 2020.

10. Ethiopian Monitor COVID-19: over 1300 Health Workers Tested Positive. Ethiopian Monitor; 2020. Available from: https://ethiopian monitor.com/2020/09/17/covid-19-over-1-300-health-workers-testedpositive/. Accessed October 15, 2020

11. L CX R, Wang Y, Wu W, Zhang L, Tan X. Risk factors of healthcare workers with corona virus disease 2019: a retrospective cohort study in a designated hospital of Wuhan in China. Clin Infect Dis. 2020. doi:10.1016/j.cmi.2020.08.038
12. WHO. Infection prevention and control during healthcare when novel coronavirus (nCoV) infection is suspected; 2020. Available from: https://www.who.int/publications-detail/infection-preventionandcontrol-during-health-care-when-novel-coronavirus-(ncov)infection-is-suspected. Accessed September 20, 2020.

13. WHO. Risk Assessment and Management of Exposure of Healthcare Workers in the Context of COVID-19 Geneva2020. Available from: https://apps.who.int/iris/handle/10665/331496. Accessed September 29, 2020.

14. CDC. Risk Assessment for Healthcare Workers Exposed to Persons with COVID-19; 2020. Available from: https://www.cdc.gov/corona virus/2019-ncov/downloads/appendix-1-hcw-risk-assessment-tool. pdf. Accessed June 1, 2020

15. Chan AT. Risk of COVID-19 among frontline healthcare workers; 2020. Available from: http://doi.org/10.1101/2020.04.29.20084111. Accessed September 19, 2020.

16. Ontario Agency for Health Protection and Promotion. COVID-19what we know so far about ... the risks to health care workers. Toronto, ON: Queen's Printer for Ontario; 2020. Available from: https://www.publichealthontario.ca/-/media/documents/ncov/what-we -know-risks-feb-21-2020.pdf?la=en. Accessed October 9, 2020.

17. J ZM W, Liu F. Reasons for healthcare workers becoming infected with novel coronavirus disease 2019 (COVID-19) in China. J Hosp Infect. 2020;105.

18. Bai Y, Wang X, Huang Q. SARS-CoV-2 infection in health care workers: a retrospective analysis and a model study. medRxiv. 2020.

19. Heinzerling A, Stuckey MJ, Scheuer T, et al. Transmission of COVID-19 to Health Care Personnel during Exposures to a Hospitalized Patient. Antimicrobial Resis Infect Control. 2021. doi:10.15585/mmwr.mm6915e5.

20. Lapolla P, Lee R, Lee R. Deaths from COVID-19 in healthcare workers in Italy-what can we learn? Infect Control Hosp Epidemiol. 2020;42(3):364-365. doi:10.1017/ice.2020.241.

21. Gong H, Feng H, Yu L, et al. COVID-19 infection among medical staff in Wuhan: a retrospective study from a single-center. Chest. 2020;158(4):1409-1412. doi:10.1016/j.chest.2020.05.529.

22. Rezaul K, Sushil K, Afsarunnesa S, et al. Hand Hygiene and Personal Protective Equipment in Healthcare Settings During COVID-19 Pandemic in Bangladesh. Bangladesh J Medicine. 2020;31:69-75. doi:10.3329/bjm.v31i2.48535

23. A KJ S, Nag VL. Screening for Methicillin-resistant Staphylococcus aureus Carriage on the Hands of Healthcare Workers: an Assessment for Hand Hygiene Practices. Indian J Crit Care Med. 2019;23 (12):590-592. doi:10.5005/jp-journals-10071-23296

24. England PH. Number of Coronavirus (COVID-19) Cases and Risk in the UK. Dept of Health and Social Care; 2020. Available from: http:// www.gov.uk. Accessed June 19, 2020.

25. Viswanath A, Monga P. Working through the COVID-19 outbreak: rapid review and recommendations for MSK and allied heath personnel. $J$ Clin Orthop Trauma. 2020;11(3):500-503. doi:10.1016/j.jcot.2020.03.014 


\section{Publish your work in this journal}

The International Journal of General Medicine is an international, peer-reviewed open-access journal that focuses on general and internal medicine, pathogenesis, epidemiology, diagnosis, monitoring and treatment protocols. The journal is characterized by the rapid reporting of reviews, original research and clinical studies across all disease areas. The manuscript management system is completely online and includes a very quick and fair peer-review system, which is all easy to use. Visit http://www.dovepress.com/ testimonials.php to read real quotes from published authors.

Submit your manuscript here: https://www.dovepress.com/international-journal-of-general-medicine-journal 